\section{OP0244 AN ASAS-POSITIVE MRI OF THE SACROILIAC JOINTS CAN ALSO OCCUR IN HEALTHY INDIVIDUALS, RUNNERS AND WOMEN WITH POSTPARTUM BACK PAIN}

J. de Winter ${ }^{1}$, M. de Hooge $\mathrm{e}^{2,3}$, M. van de Sande ${ }^{1}$, J. de Jong ${ }^{1}$, L. van Hoeven ${ }^{4}$, A. de Koning ${ }^{3}$, I.J. Berg ${ }^{5}$, R. Ramonda ${ }^{6}$, D. Baeten ${ }^{7}$, D. van der Heijde ${ }^{3}$, A. Weel ${ }^{4}$, R. Landewé ${ }^{7,8} .{ }^{1}$ Department of Clinical Immunology and Rheumatology, Amsterdam Rheumatology and immunology Center, Academic Medical Center/ University of Amsterdam, Amsterdam, Netherlands; ${ }^{2}$ Department of Rheumatology, VIB Inflammation Research Center, Ghent University, Ghent, Belgium; ${ }^{3}$ Department of Rheumatology, Leiden University Medical Center, Leiden; ${ }^{4}$ Department of Rheumatology, Maasstad Ziekenhuis, Rotterdam, Netherlands; ${ }^{5}$ Department of Rheumatology, Diakonhjemmet Hospital, Oslo, Norway; ${ }^{6}$ Department of Rheumatology, University of Padua, Padua, Italy, ${ }^{7}$ Department of Clinical Immunology and Rheumatology, AMC, Amsterdam; ${ }^{8}$ Department of Rheumatology, Zuyderland Medical Center, Heerlen, Netherlands

Background: Inflammation shown on MRI of the sacroiliac joint (MRI-SI) is prevalent in $\operatorname{axSpA}( \pm 30 \%)$ but the specificity is not well known.

Objectives: To compare MRI of the sacroiliac joints (MRI-SI) of healthy, symptomless individuals and those with known mechanical strain acting upon SI joints to axial spondyloarthritis (axSpA) and chronic back pain (CBP) patients.

Methods: Three trained, calibrated and blinded readers randomly scored MRI-SI of 172 subjects: 47 healthy individuals without current/past back pain(; 47 axSpA patients from the SPondyloArthritis Caught Early (SPACE) cohort (with a previously confirmed positive MRI-SI); 47 CBP controls (irrespective of MRI-SI results) from the SPACE cohort; 7 women with postpartum back pain; and 24 frequent runners. Readers scored according to the ASAS definition and SPARCC score.

Results: Of the 47 healthy volunteers, $11(23.4 \%)$ had a positive MRI-SI, compared to 43 of $47(91.5 \%)$ positive axSpA patients and 3 of $47(6.4 \%)$ CBP patients. Of the runners, 3 of $24(12.5 \%)$ and of the women with postpartum back pain 4 of $7(57.1 \%)$ had a positive MRI-SI. Using a SPARCC cut-off of $\geq 2$ for positivity, $12 / 47$ and healthy volunteers $(25.5 \%), 46 / 47$ positive axSpA patients (97.9\%), 5/47 CBP controls (10.6\%), 4/24 runners (16.7\%) and 4/7 women with postpartum back pain (57.1\%) were positive. 'Deep' BME-lesions were not found in healthy volunteers, CBP patients and runners, but in 38 of 47 positive axSpA patients (80.9\%) and in 1 of 7 women with postpartum back pain (14.3\%).

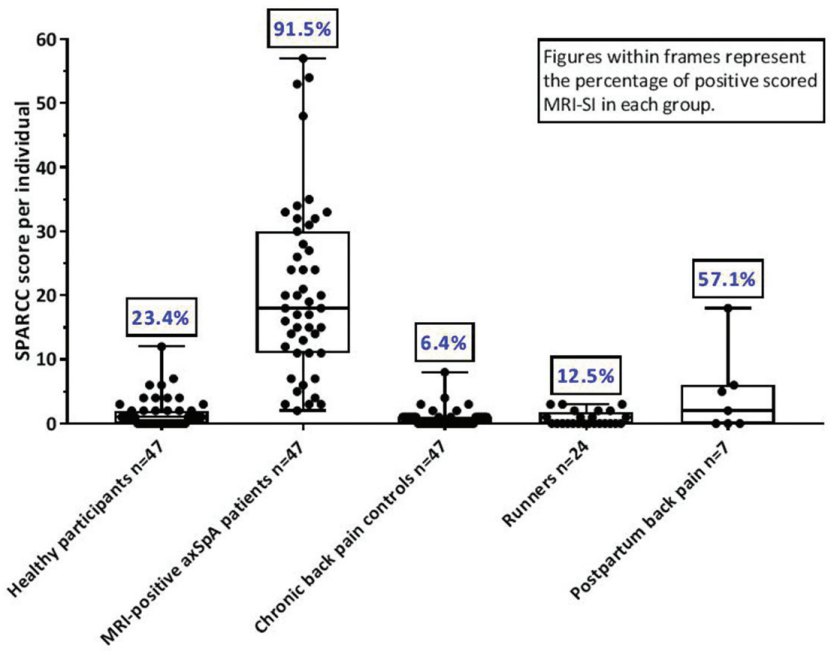

Conclusions: A substantial proportion of healthy individuals without current/past back pain has a positive MRI-SI according to the ASAS definition. Deep (extensive) BME lesions are exclusively found in axSpA patients.

\section{REFERENCE:}

[1] van Hoeven L, Luime JJ, et al. Bone marrow edema and structural lesions in the sacroiliac joint in a large cohort of patients with axial spondyloarthritis, chronic low back pain and healthy controls. ACR Annu Meet 2013;2889.

Disclosure of Interest: None declared

DOI: 10.1136/annrheumdis-2018-eular.5213

\section{OP0245 ABILITY OF MRI OF THE SACROILIAC JOINTS TO DIFFERENTIATE PATIENTS WITH AXIAL SPONDYLOARTHRITIS FROM WOMEN, WHO HAVE GIVEN BIRTH, PATIENTS WITH DISC HERNIATION, PERSONS WITH HARD PHYSICAL WORK, LONG- DISTANCE RUNNERS AND HEALTHY MALES}

S. Seven ${ }^{1}$, P. Hededal ${ }^{1}$, M. Østergaard ${ }^{1}$, L. Morsel-Carlsen ${ }^{1}$, I.J. Sørensen ${ }^{1}$, B. Bonde ${ }^{2}$, G. Thamsborg ${ }^{1}$, O. Hendricks ${ }^{3}$, N.R. Jørgensen ${ }^{1}$, S.J. Pedersen ${ }^{1}$. ${ }^{1}$ Depts. of Rheumatology (COPECARE), Radiology and Biochemistry, Rigshospitalet, Glostrup; ${ }^{2}$ The Birthe Bonde Clinic of Physioterapy, Copenhagen; ${ }^{3}$ Kong Christians X's Gigthospital, Gråsten, Denmark

Background: Sacroilitis detected by MRI plays a central role in the ASAS (Assessment of Spondyloarthritis International Society) classification criteria for axial spondyloarthritis (axSpA $)^{1}$. However, both false positives and false negatives have been reported. We have little knowledge of the best MRI approach to separate AxSpA from other conditions that may appear like sacroiliitis.

Objectives: To assess the value of different types of MRI SIJ lesions to differentiate axSpA from other conditions.

Methods: In this prospective cross-sectional study, the MASH study, 204 participants, age $\leq 45$ years were enrolled. All participants with pain should have VAS pain $>2$ (on a scale $0-10$ ) for $\geq 2$ months. Women with and without pain after pregnancy, patients with disc herniation and all participants without pain were not allowed to have any clinical SpA features or rheumatologic conditions. Information on HLA-B27 and CRP were not available until after the study. The study included 41 patients with axSpA, 46 women with and 14 without pain respectively related to pregnancy/labour $\leq 12$ months, 25 patients with lumbar disc herniation, 26 persons with hard physical jobs (cleaning assistants), 23 long-distance runners ( $\geq 30 \mathrm{~km} /$ week) and 29 healthy men. All participants underwent clinical, laboratory and MRI examination including STIR and T1-weighted sequences of the SIJs. MRIs were evaluated in random order according to the Spondyloarthritis Research Consortium of Canada SIJ MRI scores for inflammation ${ }^{2}$ and structural lesions ${ }^{3}$ by two experienced readers blinded to all clinical data.

Results: The 204 participants comprised $41.2 \%$ males, had a mean (min-max) age of $33.2(19 ; 45)$ years, and 22\% were HLA-B27 positive. The table 1 below shows the clinical characteristics within each participant group, and the preliminary MRI results based on one reader. MRI bone marrow oedema, fat metaplasia and erosions were frequently present in patients with axSpA, but were also seen in the other groups of study participants with and without pain, particularly in women with postpartum pain. MRI backfill and ankylosis were only seen in patients with axSpA.

Abstract OP0245 - Table 1. Clinical characteristics, SPARCC scores and distribution of SPARCC scores

\begin{tabular}{|c|c|c|c|c|c|c|c|c|}
\hline \multicolumn{9}{|c|}{ Cinitcal characteristics, SPARCC scores and distribution of SPARCC scores } \\
\hline & & $\begin{array}{l}\text { AxSpA } \\
(\mathrm{N}-41)\end{array}$ & $\begin{array}{c}\text { Post- } \\
\text { partum } \\
\text { w/ pain } \\
(\mathrm{N}=46)\end{array}$ & \begin{tabular}{|c|} 
Post- \\
partum w/o \\
Pain \\
$(\mathrm{N}=14)$
\end{tabular} & \begin{tabular}{|c|} 
Dise \\
Dertalation \\
(Ne25) \\
\end{tabular} & $\begin{array}{l}\text { Cleaning } \\
\text { staff } \\
(N=26)\end{array}$ & $\begin{array}{c}\text { Long } \\
\text { distance } \\
\text { Ruaners } \\
(\mathrm{N}=23)\end{array}$ & $\begin{array}{c}\begin{array}{c}\text { Healthy } \\
\text { men }\end{array} \\
(\mathrm{N}=29)\end{array}$ \\
\hline \multicolumn{2}{|l|}{ Age } & \begin{tabular}{|c|}
30.9 \\
$30.0(19: 44)$ \\
\end{tabular} & \begin{tabular}{|c|}
32.6 \\
$325(26 ; 41)$
\end{tabular} & \begin{tabular}{|c|}
33.1 \\
$325(27: 41)$ \\
\end{tabular} & \begin{tabular}{|c|}
352 \\
$37.0(21: 43)$ \\
\end{tabular} & \begin{tabular}{|c|}
39.1 \\
$39.0(28: 45)$
\end{tabular} & \begin{tabular}{|c|}
32.7 \\
$32.0(22 ; 43)$ \\
\end{tabular} & \begin{tabular}{|c|}
30.9 \\
$30.0(20: 45)$
\end{tabular} \\
\hline \multicolumn{2}{|l|}{ Sale sex } & $26(63.4)$ & $0(0)$ & $0(0)$ & $11(44.0)$ & $0(0)$ & $18(78.3)$ & $29(100.0)$ \\
\hline \multicolumn{2}{|l|}{ HLA-B27 } & $33(80.5)$ & $5(10.9)$ & $1(7.1)$ & $0(0)$ & $0(0)$ & $1(4.3)$ & $4(138)$ \\
\hline \multicolumn{2}{|l|}{ CRP (mgl) } & $\begin{array}{c}11.4 \\
60(0.3 ; 58)\end{array}$ & \begin{tabular}{c|}
1.6 \\
$0.8(0.3 ; 7.1)$
\end{tabular} & \begin{tabular}{|c|}
2.4 \\
$0.7(0.3 \cdot 13)$
\end{tabular} & $\begin{array}{c}22 \\
0.9(0.3 ; 14)\end{array}$ & \begin{tabular}{|c|}
2.6 \\
$1.0(0.3: 20)$
\end{tabular} & \begin{tabular}{|c|}
1.4 \\
$0.4(0.3 ; 7.6)$
\end{tabular} & $\begin{array}{c}0.9 \\
0.3(0.3 .49)\end{array}$ \\
\hline \multicolumn{2}{|l|}{ Child births } & $\begin{array}{c}1.7 \\
2.0(0 ; 2)\end{array}$ & $\begin{array}{c}1.5 \\
1.0(1: 4)\end{array}$ & $\begin{array}{c}19 \\
2.0(1 ; 3)\end{array}$ & $\begin{array}{c}1.6 \\
2.0(0,3)\end{array}$ & \begin{tabular}{|c|}
25 \\
$2.5(0.5)$
\end{tabular} & $\begin{array}{c}0.5 \\
0(0,2)\end{array}$ & NA \\
\hline \multicolumn{2}{|c|}{ SPARCC Innammation- } & \begin{tabular}{|c|}
111.4 \\
$10.0(0,43)$
\end{tabular} & \begin{tabular}{c|}
4.2 \\
$1.0(0,21)$ \\
\end{tabular} & $\begin{array}{c}15 \\
0(0.8)\end{array}$ & $\begin{array}{c}0.3 \\
0(0,5)\end{array}$ & $\begin{array}{c}0.7 \\
0(0 ; 5)\end{array}$ & $\begin{array}{c}0.3 \\
0(0 ; 4)\end{array}$ & $\begin{array}{c}0.2 \\
0(0.2)\end{array}$ \\
\hline \multicolumn{2}{|l|}{ SPARCC Fat } & $\begin{array}{c}11.6 \\
9.0(0,40)\end{array}$ & $\begin{array}{c}0.6 \\
0(0 ; 14)\end{array}$ & $\begin{array}{c}0.6 \\
0(0.7)\end{array}$ & $\begin{array}{c}0.4 \\
0(0,4)\end{array}$ & $\begin{array}{c}0.2 \\
0(0 ; 2)\end{array}$ & $\begin{array}{c}0.4 \\
0(0 ; 5)\end{array}$ & $\begin{array}{c}0.7 \\
0(0 ; 11)\end{array}$ \\
\hline \multicolumn{2}{|l|}{ SPARCC Erosion } & $\begin{array}{c}4.6 \\
1(0.15)\end{array}$ & $\begin{array}{c}0.6 \\
0(0: 17)\end{array}$ & $\begin{array}{c}0 \\
0(0,0)\end{array}$ & $\begin{array}{c}0 \\
0(0,1)\end{array}$ & $\begin{array}{c}0.1 \\
0(0,2)\end{array}$ & $\begin{array}{c}0.1 \\
0(0,2)\end{array}$ & $\begin{array}{c}0.1 \\
0(0,3)\end{array}$ \\
\hline \multicolumn{2}{|l|}{ SPARCC Backfill } & $\begin{array}{c}5.9 \\
3.0(0 ; 20)\end{array}$ & $\begin{array}{c}0 \\
0(0,0)\end{array}$ & $\begin{array}{c}0 \\
0(0 ; 0)\end{array}$ & $\begin{array}{c}0 \\
0(0,0)\end{array}$ & $\begin{array}{c}0 \\
0(0 ; 0)\end{array}$ & $\begin{array}{c}0 \\
0(0 ; 0)\end{array}$ & $\begin{array}{c}0 \\
0(0,0)\end{array}$ \\
\hline \multicolumn{2}{|l|}{ SPARCC Ankylosis } & $\begin{array}{c}4.0 \\
0(0 ; 20)\end{array}$ & $\begin{array}{c}0 \\
0(0,0)\end{array}$ & $\begin{array}{c}0 \\
0(0,0)\end{array}$ & $\begin{array}{c}0 \\
0(0,0)\end{array}$ & $\begin{array}{c}0 \\
0(0 ; 0)\end{array}$ & $\stackrel{0}{0}$ & $\begin{array}{c}0 \\
0(0,0)\end{array}$ \\
\hline \multirow{4}{*}{$\begin{array}{l}\text { SPARCC } \\
\text { IInammation" }\end{array}$} & score $\geq 1$ & $28(68)$ & $24(52)$ & $5(36)$ & $3(12)$ & $5(19)$ & 3(13) & $4(14)$ \\
\hline & as & $26(63)$ & $21(46)$ & $4(29)$ & $1(4)$ & 3(12) & 1(4) & $0(0)$ \\
\hline & st & $25(61)$ & $13(28)$ & $1(7)$ & $1(4)$ & 1(4) & $0(0)$ & $0(0)$ \\
\hline & $=10$ & $21(51)$ & $8(17)$ & $0(0)$ & $0(0)$ & $0(0)$ & $0(0)$ & $0(0)$ \\
\hline \multirow{4}{*}{$\begin{array}{l}\text { SPARCC } \\
\text { Fat }\end{array}$} & at & $33(81)$ & s(11) & $2(14)$ & $3(12)$ & $2(8)$ & $2(9)$ & $3(10)$ \\
\hline & 2s & $29(1)$ & 3(n) & $1(7)$ & $2(8)$ & $0(0)$ & $2(9)$ & $2(7)$ \\
\hline & $=5$ & $27(66)$ & $2(4)$ & 1(i) & $0(0)$ & $0(0)$ & 1(4) & $2(n)$ \\
\hline & $=10$ & $20(49)$ & $1(2)$ & $o(0)$ & $0(0)$ & $0(0)$ & $0(0)$ & 1(3) \\
\hline \multirow{4}{*}{\begin{tabular}{|l} 
SPARCC \\
Erocion
\end{tabular}} & $\geq 1$ & $27(66)$ & $4(9)$ & $0(0)$ & 1(4) & 1(4) & 1(4) & $2(7)$ \\
\hline & की & 18 (44) & $2(4)$ & $0(0)$ & $0(0)$ & $0(0)$ & $0(0)$ & 1(3) \\
\hline & कs & $16(39)$ & $2(4)$ & $0(0)$ & $0(0)$ & $0(0)$ & $0(0)$ & $0(0)$ \\
\hline & $=10$ & $10(24)$ & 1(2) & $o(0)$ & $O(0)$ & $0(0)$ & $0(0)$ & $0(0)$ \\
\hline SPARCC Backfil & $\geq 1$ & $23(56)$ & $0(0)$ & $0(0)$ & $0(0)$ & $0(0)$ & $0(0)$ & $0(0)$ \\
\hline 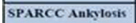 & at & $17(42)$ & $0(0)$ & $0(0)$ & $0(0)$ & $0(0)$ & $0(0)$ & $0(0)$ \\
\hline
\end{tabular}


Conclusions: Inflammatory lesions, fat metaplasia and erosions were most frequently occurring in patients with axSpA, but also in women with postpartum pain. The SPARCC-scores cannot separate the different groups entirely. Further detailed analysis of lesions may help differentiate axSpA from other conditions.

\section{REFERENCES:}

[1] Rudwaleit M, et al. Ann Rheum Dis 2009;68(6):777-783.

[2] Maksymowych WP, et al. Arthritis Rheum 2005;53:703-9.

[3] Maksymowich WP, et al. J Rheumatol 2015;42:79-86.

Disclosure of Interest: None declared

DOI: 10.1136/annrheumdis-2018-eular.2586

\section{OP0246 INFLAMMATION ON MRI OF SPINE AND SACROILIAC JOINTS IS HIGHLY PREDICTIVE OF STRUCTURAL DAMAGE IN AXIAL SPONDYLOARTHRITIS: THE 5 YEARS DATA OF THE DESIR COHORT}

A. Sepriano ${ }^{1}$, S. Ramiro ${ }^{1}$, R. Landewé ${ }^{2}$, M. Dougados $^{3}$, D. van der Heijde ${ }^{1}$. ${ }^{1}$ Rheumatology, Leiden University Medical Centre, Leiden; ${ }^{2}$ Rheumatology, Amsterdam Rheumatology and Clinical Immunology Center (ARC), Amsterdam, Netherlands; ${ }^{3}$ Rheumatology, Hôpital Cochin, Hôpitaux de Paris, Paris, France

Background: The effect of local inflammation on structural damage in patients (pts) with axial spondyloarthritis is not well known.

Objectives: We aimed to test the possible effect of inflammation on structural damage both assessed by MRI and at the level of the spine and the SIJ.

Methods: Pts with recent onset ( $\leq 3$ years) axSpA (according to the treating rheumatologist) from the DESIR cohort were included. MRI of the SIJ (MRI-SIJ) and spine (MRI-spine) were obtained at baseline (BL), 2 and 5 years and scored by 3 trained central readers unaware of the chronology. Bone Marrow Oedema (BME) at MRI-SIJ was assessed according to ASAS definition and at the MRI-spine by the presence of $\geq 3$ lesions. Structural damage in the SIJ (MRI-SIJ-STR) and in the spine (MRI-spine-STR) was defined by $\geq 3$ fatty lesions. The $\%$ of structural net progression (number of 'progressors' minus the number of 'regressors' divided by the total number of pts) was assessed in subgroups according to CRP and BME status at BL. The effect of BME on MRI-SIJ on MRI-SIJ-STR and of BME on MRI-spine on MRI-spine-STR was evaluated using two types of binomial generalised estimating equations (GEE) models: i. effect at BL on 5 years incorporating measurements from all readers (GEE adjusted for reader); ii. effect of BME over 5 years (longitudinal time-lagged models with auto-regression). The final models were adjusted for variables proved to confound the association of interest (variables tested: age, gender, HLA-B27, smoking status, CRP, BASDAI, ASDAS, treatment with NSAIDs and TNFi).

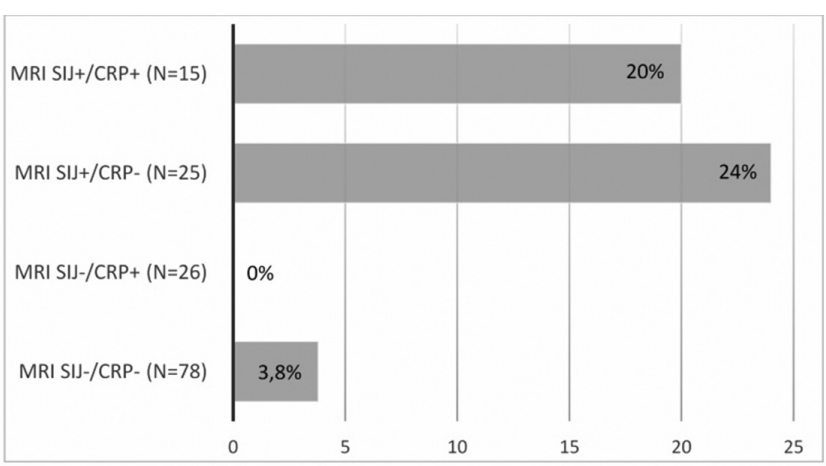

Abstract OP0246 - Figure 1 Net progression from MRI-SIJ-STR negative to MRI-SIJ-STR positive ( $\geq 3$ fattylesions) according to baseline objective inflammatory markers:

Results: In total, 151 and 145 pts had complete 5 year MRI-SIJ and MRI-spine data available from 3 readers, respectively. Of the 151 pts with complete MRI-SIJ data, the net\% pts who switched from MRI-SIJ-STR negative to positive ranged from $3.8 \%$ to $24 \%$ according to the presence of objective signs of inflammation at BL (figure 1). Low number of pts did not allow for similar analysis in the spine. In the multivariable analysis, both the presence of BME at MRI-SIJ $(\mathrm{OR}=4.2[95 \%$ Cl: 2.4 to 7.3$]$ ), and BME at MRI-spine (OR=8.9 [95\% Cl: 2.1-38.7]) at baseline were highly predictive of MRI-SIJ and MRI-spine structural progression respectively 5 years later, adjusting for CRP (only factor found to confound the association of interest). Similar positive associations were found in the longitudinal models testing the effect of BME on MRI-SIJ-STR and MRI-spine-STR over 5 years (table 1).
Abstract OP0246 - Table 1 Effect of inflammation on MRI (ASAS definition of sacroiliitis and BME in the spine) on binary MRI structural outcomes

\begin{tabular}{lcc}
\hline & $\begin{array}{c}\geq 3 \text { fatty lesions on } \\
\text { MRI-SIJ }\end{array}$ & $\begin{array}{c}\geq 3 \text { fatty lesions on } \\
\text { MRI-Spine }\end{array}$ \\
\hline Effect of BMI on: & OR $(95 \% \mathrm{Cl})$ & OR $(95 \% \mathrm{Cl})$ \\
& $(\mathrm{n}=144-197)$ & $(\mathrm{n}=145-197)$ \\
By GEE adjusted for reader & $4.2(2.4 ; 7.3)^{\star}$ & $8.9(2.1 ; 38.7)^{\star}$ \\
$\begin{array}{l}\text { By longitudinal GEE adjusted for reader and } \\
\text { repeated measurements }\end{array}$ & $5.1(2.7 ; 9.6) £$ & $15.6(4.8 ; 50.3) £$ \\
& &
\end{tabular}

* Adjusted for CRP at baseline; £ adjusted for time-varying lagged ASDAS-CRP

Conclusions: Our results show that local inflammation is strongly associated with the development of structural damage over 5 years both in the SIJ and spine in early axSpA and that this effect is independent of systemic inflammation.

Disclosure of Interest: None declared

DOI: 10.1136/annrheumdis-2018-eular.1748

\section{OP0247 PERFORMANCE OF REFERRAL STRATEGIES FOR SPONDYLOARTHRITIS: A POPULATION-BASED NATIONWIDE STUDY}

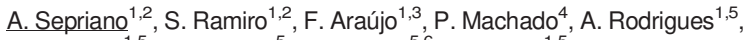
N. Gouveia ${ }^{1,5}, \mathrm{M}$. Eusébio ${ }^{5}, \mathrm{H}$. Canhão ${ }^{5,6}, \mathrm{~J}$. Branco ${ }^{1,5}$, on behalf of EpiReumaPt Team. ${ }^{1}$ CEDOC, NMS, Lisbon, Portugal; ${ }^{2}$ Rheumatology, Leiden University Medical Centre, Leiden, Netherlands; ${ }^{3}$ Rheumatology, Hospital Ortopédico de Sant 'Ana, Cascais, Portugal: ${ }^{4}$ Rheumatology, University College London, London, UK; ${ }^{5}$ EpiReumaPt Investigation Team; ${ }^{6}$ CEDOC, EpiDoC Unit, NOVA Medical School and National School of Public Health, Universidade Nova de Lisboa, Lisbon, Portugal

Background: Several strategies have been proposed to promote early referral of patients with axial spondyloarthritis (axSpA), but consensus on the 'best' strategy is yet to be achieved. Moreover, few studies compared referral strategies (RS) head-to-head and, up to now, none has neither evaluated these in a 'nationwide' setting (external validity) nor assessed the entire spectrum of SpA (i.e. axSpA and peripheral SpA).

Objectives: To evaluate the performance of the screening strategy for SpA of a nationwide epidemiological study (EpiReumaPt), as compared to previously proposed RS.

Methods: EpiReumaPt was a three-stage national health survey (2011-2013) where, in the first phase, 10661 adult participants were randomly selected and interviewed using a structured face-to-face questionnaire that included screening for rheumatic diseases (RD), such as SpA. In the second phase, positive screenings for $\geq 1$ rheumatic complaint plus $20 \%$ negative screenings were invited for an assessment by the rheumatologist. Finally, 3 rheumatologists revised all the information and defined the final diagnosis by consensus. All participants of the second phase were included $(n=3,877)$. Each RS (table 1 ) was tested against the SpA revised diagnosis using the following metrics: sensitivity, specificity, positive predictive value (PPV), and post-test probability of disease given a negative test (1-negative predictive value). RS with an imaging (e.g. MRI) or laboratory component (e.g. CRP, HLA-B27) were modified (by excluding these components) given limited data obtained in the survey (table 1). A weighting factor was used to take the survey design into account.

Results: From the total 3877 participants, 92 received a SpA diagnosis [weighted prevalence: $1.6 \%(95 \% \mathrm{Cl}: 1.2$ to 2.1$)$ ], 3107 other RD diagnosis [e.g. knee osteoarthritis (31\%)] and 678 no RD diagnosis. The ASAS RS was the most sensitive (85\%) followed by the EpiReumaPt strategy (72\%) (table 1). The ASAS and EpiReumaPt RS had the lowest post-test probabilities of SpA in the presence of negative screening $(0.6 \%$ and $0.7 \%$ respectively), thus, yielding a marked decrease in the probability of disease if negative $\left[(1.6-0.6) / 1.6^{*} 100=63 \% ;(1.6-0.7) /\right.$ $1.6^{*} 100=56 \%$ respectively). On the other hand, the likelihood of SpA increased by $38 \%(2.2-1.6) / 1.6 * 100)$ and $119 \%(3.5-1.6) / 1.6 * 100)$ in case of a positive ASAS and EpiReumaPt RS, respectively. Brandt III was the least sensitive strategy in this study and not contributive to excluding SpA (1-NPV: $1.5 \%$; pre-test probability: $1.6 \%$ ), but expectedly increased the likelihood of SpA by 3.8 times if positive. The performance of the remaining $\mathrm{RS}$ is described in the table 1. 